\title{
A AUTOAVALIAÇÃO NA APRENDIZAGEM DE LÍNGUA INGLESA: EXPERIÊNCIA EM PROJETO TELECOLABORATIVO NO ENSINO MÉDIO PROFISSIONALIZANTE
}

\author{
Patrícia da Silveira (Estudos da Linguagem/UEL) \\ Profa. Viviane Bagio Furtoso (Orientadora)
}

\section{RESUMO}

As orientações de língua inglesa para o ensino médio profissionalizante priorizam a formação do sujeito para a vida e para o mundo social do trabalho. Dessa forma, a aprendizagem de língua inglesa no contexto de telecolaboração é uma alternativa que vai ao encontro dessa proposta, uma vez que possibilita aos estudantes uma experiência de comunicação real desse idioma durante as interações orais via Skype com falantes de outros países. Isto posto, o presente trabalho visa apresentar os resultados preliminares de uma pesquisa em andamento, que objetiva investigar o papel da autoavaliação como reguladora do processo de aprendizagem de língua inglesa no contexto de telecolaboração. Para o levantamento de dados foram analisadas as questões que compõem a ficha de autoavaliação que os participantes do projeto BOM TO SEE USTED preenchem após as sessões de práticas orais. Tais questões foram categorizadas de acordo com as fases do processo de regulação sendo organizadas através da recolha e interpretação de informações obtidas a partir das interações entre os participantes e da adequação e/ou readequação das atividades relacionadas a tais práticas. Os resultados obtidos até o presente momento apontam a autoavaliação como potencializadora do processo de aprendizagem, uma vez que possibilita ao estudante a corresponsabilidade por esse processo, permitindo-lhe refletir sobre seu desempenho, e, a partir dessas reflexões, tornar-se agente ativo de sua aprendizagem.

Palavras-chave: autoavaliação; ensino médio profissionalizante; telecolaboração.

\section{CONTEXTUALIZANDO O ESTUDO}

O processo de aprendizagem de línguas tem se tornado diversificado e híbrido, expandindo-se para além dos limites da sala de aula ${ }^{1}$, haja vista o uso das Tecnologias de Informação e Comunicação (TIC) como ferramentas facilitadoras de comunicação síncrona e assíncrona, tais como Skype, Chat rooms e Whatsapp, que são disponibilizadas na internet.

O uso dessas ferramentas permite que a aprendizagem de línguas possa ser intensificada de forma colaborativa, uma vez que aprendizes de diversos países podem desenvolver suas habilidades comunicativas na língua alvo através de interações online.

\footnotetext{
${ }^{1} \mathrm{O}$ termo "sala de aula" será usado neste artigo como representativo do contexto presencial, distinguindose, assim, do contexto telecolaborativo. Dessa forma, ao lermos "sala de aula" entendemos "sala de aula presencial"'.
} 


\section{SEMINÁRIO DE PESQUISA EM CIÊNCIAS HUMANAS - SEPECH \\ Humanidades, Estado e desafios didático-científicos \\ Londrina, 27 a 29 de julho de 2016}

Entretanto é necessário avaliar como tal prática é capaz de intensificar a aprendizagem de línguas, assim como, identificar o papel de cada um dos atores envolvidos nesse processo.

Para tanto é importante que professor e estudante tenham definidos os objetivos que querem alcançar na aprendizagem da língua alvo com o uso das TIC e, a partir disso, avaliem suas práticas constantemente. É nesse contexto que a autoavaliação pode ser utilizada como reguladora do processo de aprendizagem.

Dessa forma, este artigo tem como objetivo apresentar resultados preliminares de um estudo de caráter qualitativo que busca investigar o papel da autoavaliação como reguladora do processo de aprendizagem de língua no contexto de telecolaboração. Os dados foram coletados por meio de uma ficha de autoavaliação, preenchida pelos estudantes do projeto BOM TO SEE USTED (BTSU) ${ }^{2}$.

$\mathrm{O}$ artigo foi dividido em quatro seções, dessa forma, a primeira seção apresenta considerações sobre o uso das TIC e do contexto telecolaborativo na aprendizagem de língua, a segunda aborda a questão da autoavaliação como reguladora da aprendizagem, a terceira seção remete-se ao projeto BTSU e o uso da ficha de autoavaliação naquele contexto e a quarta apresenta as considerações preliminares.

\section{O CONTEXTO TELECOLABORATIVO: APROXIMANDO MUNDOS}

A diversidade e hibridização, oriundas pelo uso das TIC, tem como objetivo complementar o trabalho que é desenvolvido em sala de aula (SANTAELLA, 2013) e possibilitar aos estudantes aprender e/ou aprimorar a aprendizagem de línguas-culturas, percorrer o mundo e apropriar-se dos mais diversos saberes sem necessariamente viajar para outros países (FURTOSO, 2011), criando novas interações sociais a partir de redes de interesses comuns (MARCUSCHI, 2004) e culturas diversas.

A partir do contexto online, que também possui caráter de inclusão social devido ao baixo custo (TELLES, 2006), é possível otimizar as aulas de línguas utilizando-se dessa acessibilidade entre os povos e oportunizar a interação real com nativos e outros falantes da língua alvo (PAIVA, 2001).

Segundo Belloni (1999), a interação é uma ação de intersubjetividade recíproca entre sujeitos, sendo caracterizada por Primo (1998) como mútua, devido as suas relações interdependentes e processos de negociação, em que cada interlocutor participa da construção comunicativa da interação, afetando-se mutuamente.

Para Furtoso (2011), essa aproximação/interação permite que o aluno deixe de realizar simulações comunicativas pautadas pelo professor para realizá-las em contexto real através do contato com pessoas do mundo todo, estabelecendo, assim, o que Paiva (2001) apresenta como a construção social da aprendizagem através de práticas colaborativas.

Segundo Ciavel-Arroitia e Pennock-Speck (2015),

o objetivo da comunicação mediada por computador (CMC) é facilitar a existência de interações comunicativas colaborativas entre os estudantes

\footnotetext{
${ }^{2} \mathrm{O}$ projeto em questão será detalhado na seção 3 deste artigo.
} 


\section{SEMINÁRIO DE PESQUISA EM CIÊNCIAS HUMANAS - SEPECH \\ Humanidades, Estado e desafios didático-científicos \\ Londrina, 27 a 29 de julho de 2016}

que promovam tanto a aprendizagem da língua alvo quanto a aquisição de competências comunicativas interculturais. ${ }^{3}$ (p.75)

Coelho, Galante e Pires (2016) definem aprendizagem colaborativa como aprender com o outro, na qual, através de ferramentas digitais, é possível que os estudantes interajam no idioma estrangeiro, explorando a diversidade cultural e linguística. De acordo com as autoras, a "aprendizagem colaborativa online permite amplas oportunidades de desenvolver as dimensões integrais de acordo com a teoria sócio histórica, tendo como vantagem o uso do contexto online ${ }^{4, "}$ (p.2).

Nesse sentido, os trabalhos de Belz (2002, 2003a, 2003b), Telles (2006) e Telles e Vassalos (2009) ampliam o conceito de aprendizagem colaborativa introduzindo a telecolaboração como forma de potencializar esse processo.

Segundo Belz (2003a), na telecolaboração os participantes usam ferramentas de comunicação propiciadas pela internet como suporte para a interação social, diálogo, debates e trocas interculturais. Entre as ferramentas disponibilizadas, damos ênfase ao Skype que é utilizado pelo projeto citado nesse artigo.

Telles e Vassalos (2009) apontam para o uso da telecolaboração como forma de potencializar a aprendizagem uma vez que permite unir dois contextos mediantes a associação de ambientes virtuais a recursos de escrita, voz e imagem.

Ao propiciar tal prática telecolaborativa de aprendizagem de idiomas aos estudantes busca-se formar indivíduos para além de suas competências linguísticocomunicativas, levando-o a uma nova maneira de ver o mundo e a si próprio (BRASIL, 2006)

De acordo com Fino (2001), a aprendizagem com o auxílio de outros mais experientes é necessariamente mais produtiva que a aprendizagem a solo. É durante o processo de mediação que os aprendizes desenvolvem a língua através da participação em atividades sociais e de interação que demandam engajamento e senso crítico (COELHO; GALANTE; PIRES, 2016; LANTOLF; THRONE; POEHER, 2015).

Isto posto, acreditamos que seja possível otimizar a aprendizagem do estudante com o uso das TIC, mais precisamente do contexto telecolaborativo, uma vez que, se bem aproveitado, pode tornar-se um meio eficaz de lidar com as práticas pluralistas de comunicação (MARCUSCHI, 2004).

Concordamos com Garcia (2011) quando afirma que o uso da (tele)colaboração não indica que "a sala de aula precisa ser abandonada; no entanto, ela pode ser complementada e enriquecida [...] pela autenticidade das oportunidades de comunicação entre os povos" (p. 103).

Diante de tais considerações em relação ao uso das TIC e ao contexto telecolaborativo como forma de complementar as aulas de idiomas e intensificar a

\footnotetext{
${ }^{3}$ The ultimate aim of $\mathrm{CMC}$ is to facilitate the existence of collaborative conversations between students that promote both the learning of a foreign language and the acquisition of intercultural communicative skills. (CIAVEL-ARROITIA; PENNOCK-SPECK, 2015, p. 75)

${ }^{4}$ Online collaborative learning includes ample opportunities to develop the dimensions integral to SCT, with an advantage of conveniently taking place online. (Coelho D.; Galante A.; Pires A.L; 2016, p. 2)
} 


\section{SEMINÁRIO DE PESQUISA EM CIÊNCIAS HUMANAS - SEPECH \\ Humanidades, Estado e desafios didático-científicos \\ Londrina, 27 a 29 de julho de 2016}

aprendizagem, faz-se necessário refletir sobre esse processo considerando os caminhos percorridos a partir da avaliação, mais precisamente da autoavaliação.

\section{A AUTOAVALIAÇÃO COMO REGULADORA DO PROCESSO DE APRENDIZAGEM}

Se por um lado é possível destacar os aspectos positivos do uso das tecnologias na aprendizagem de línguas, por outro lado otimizar tal proposta exige reflexão e mudança de postura no que tange o ato de ensinar, por parte do professor, e aprender, por parte do estudante.

Para isso, o objetivo que se quer alcançar deve estar claro para todos os envolvidos no processo, assim como a tríade planejamento-estratégias-avaliação que permitiram alcançar tais objetivos.

Nesse sentido, segundo Luckesi (2008), a avaliação torna-se subsidiária das decisões a respeito do processo de aprendizagem, tendo em vista garantir a qualidade dos resultados que se busca.

Dessa forma, é possível criar ações constantes e crescentes no processo aprendizagem que permitam o revisitamento dos objetivos (metas) iniciais, a (re)adequação do planejamento, a (re)aplicação das estratégias e a (re)avaliação desse processo com o intuito de alcançar o objetivo (meta) estipulado.

A figura abaixo representa esse movimento crescente, em espiral, das ações observadas no processo de aprendizagem.

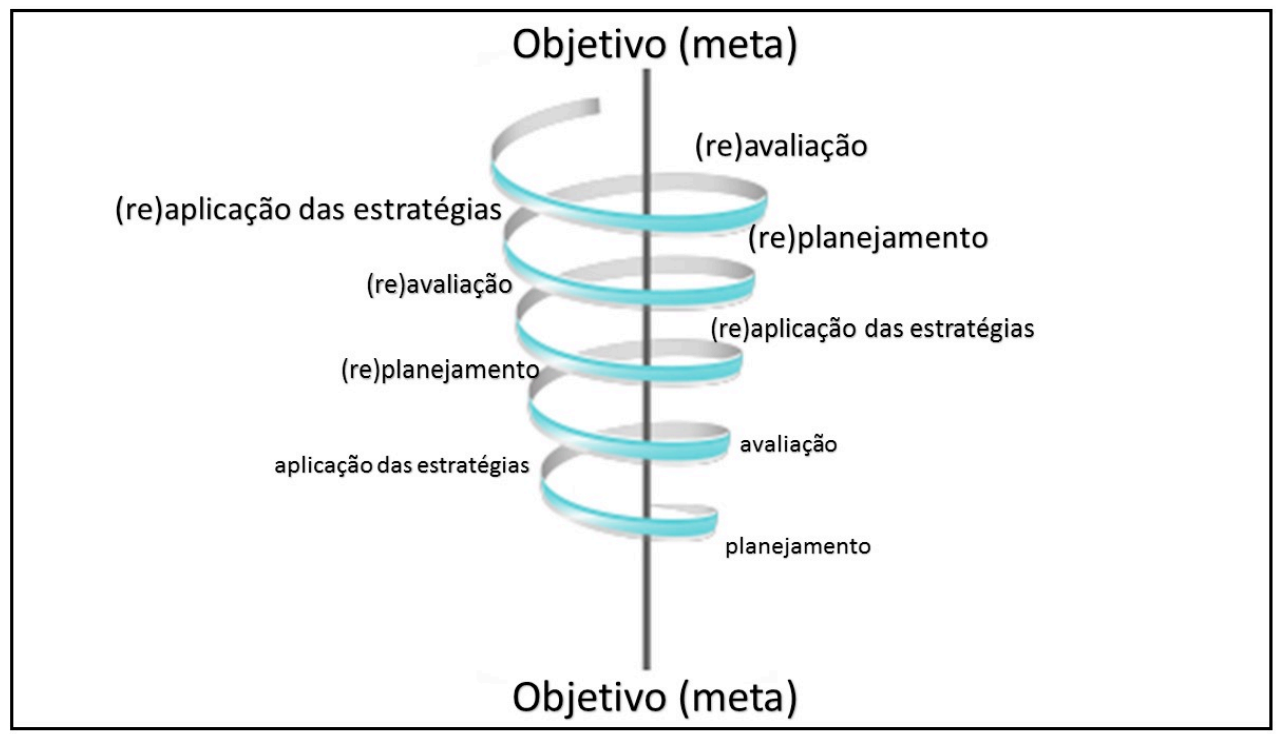

Figura 1 - Ações constantes e crescentes no processo de aprendizagem Fonte: a própria autora

Tais ações permitem que o professor e o estudante avaliem as partes do processo, uma vez que, ao se planejar uma ação para alcançar um objetivo, são propostas estratégias para facilitar esse alcance de metas e consequentemente é 


\section{SEMINÁRIO DE PESQUISA EM CIÊNCIAS HUMANAS - SEPECH \\ Humanidades, Estado e desafios didático-científicos \\ Londrina, 27 a 29 de julho de 2016}

necessário avaliar se as estratégias utilizadas nesse processo permitiram cumprir o objetivo proposto.

Esse movimento, em espiral e interdependente proposto acima, faz-se necessário uma vez que, para se chegar ao produto é necessário pensar o processo (SCARAMUCCI, 2006) e não há processo sem pensar em produto (LUCKESI, 2008).

Diversos estudos desenvolvidos a partir da avalição em contexto telecolaborativo, tais como os propostos por Cavalari (2010) e Furtoso (2011), enfatizam a autoavaliação como forma de permitir ao estudante verificar os resultados de sua aprendizagem a partir de parâmetros internos.

Para Pinto e Santos (2006)

Quem avalia aprecia o que vê. Este juízo de valor depende, por um lado, dum enunciado prescritivo que o precede, dado que não poderei apreciar sem estabelecer uma comparação com aquilo que entendo que deveria ser, e por outro, de um julgamento do observador, uma vez que não poderei estabelecer uma apreciação sem conhecer algo daquilo que estou a apreciar. (p.33)

Se o papel da autoavaliação é regular a aprendizagem, o professor assume um papel de mediador nesse processo ou par mais experiente (VYGOTSKY, apud FINO, 2001), propiciando condições ao estudante para pensar de forma autônoma (JUNCKES, 2013; FURTOSO, 2011; CAVALARI, 2010), e permitindo que ele se torne agente ativo do seu próprio processo de aprendizagem.

O processo de regulação, segundo Pinto e Santos (2006), é composto por três fases: a - recolha da informação, relacionada aos processos de aprendizagens desenvolvidos por cada estudante, apontando as metas e objetivos alcançados assim como as dificuldades e obstáculos enfrentados no processo de aprendizagem; b interpretação da informação recolhida com o intuito de compreender a situação observada; c - adaptação ou readequação das atividades propostas a partir das análises realizadas do processo.

Neste sentido a ficha de autoavaliação contempla as fases propostas acima de modo a conscientizar o estudante do caminho percorrido até então, e a partir disso, que ele seja capaz de reelaborar estratégias de autorregulação de sua aprendizagem (VIEIRA, 2013; OLIVEIRA, 2006; COSTA, 2009).

A ficha de autoavaliação, utilizada como instrumento de análise para a regulação, é apresentada na próxima seção assim como os procedimentos de coleta de dados para essa pesquisa.

\section{O PROJETO BTSU E A FICHA DE AUTOAVALIAÇÃO}

O projeto BOM TO SEE USTED (doravante BTSU) faz parte das atividades optativas oferecidas aos estudantes do ensino médio profissionalizante de uma escola pública federal do estado do Paraná. O objetivo do projeto é promover a aprendizagem de língua inglesa através do contexto online e a ficha de autoavaliação é utilizada com o intuito de levar o estudante a pensar sobre seu próprio processo de aprendizagem criando estratégias e otimizando a mesma. 


\section{SEMINÁRIO DE PESQUISA EM CIÊNCIAS HUMANAS - SEPECH \\ Humanidades, Estado e desafios didático-científicos \\ Londrina, 27 a 29 de julho de 2016}

Nesse projeto, estão inscritos cinco estudantes que, através do Skype, realizam interações orais e escritas com cinco estrangeiros de diferentes países (Canadá, Cuba, Paquistão, México e Filipinas) com o objetivo de aprender inglês.

Considerando o nível linguístico dos estudantes brasileiros (iniciantes), o projeto foi dividido em duas sessões distintas que acontecem duas vezes por semana com duração de uma hora e meia cada.

$\mathrm{Na}$ primeira sessão, denominada de Sessão de Estudo Dirigido (SED), os estudantes, juntamente com o professor, definem o tópico de conversação, as metas a serem atingidas a partir das interações e as estruturas linguísticas necessárias para a mesma, ou seja, eles elaboram um roteiro de perguntas e frases, a partir de situações cotidianas, hábitos, planos futuros e/ou atividades realizadas em algum momento no passado, descrições de lugares tais como a própria cidade, o bairro onde moram, etc. Essas perguntas e frases servem como um roteiro para facilitar a interação.

Na segunda sessão, denominada de Sessão de Prática Oral (SPO), o estudante utiliza as anotações das SED para interagir com os falantes de língua inglesa de outros países. É após essa sessão que o estudante preenche sua ficha de autoavaliação.

A ficha é composta por oito questões com o objetivo de permitir que o estudante reflita sobre sua atuação durante a prática oral, assim como o processo de sua própria aprendizagem. As questões são: 1 - Qual o assunto estudado no dia?; 2 - Qual foi o seu parceiro de hoje? Está satisfeito com a interação feita com ele? Por quê?; 3- O que você considera ter sido o momento de destaque de sua aprendizagem de hoje? Por quê?; 4Marque um X nas alternativas que você considera ter aprendido na sessão de hoje (gramática, fluência, vocabulário, pronúncia, expressões idiomáticas, gírias, compreensão oral, outros); 5- Exemplifique os itens marcados; 6- Quais as dificuldades que você teve durante a sessão de hoje?; 7- O que você acha que precisa melhorar e como? e 8- O que você espera para a próxima sessão?

É a partir da análise das respostas dos estudantes, em relação às questões da ficha proposta, que buscamos refletir sobre o impacto da autoavaliação em relação à regulação da aprendizagem pelo próprio estudante. Para tanto, as perguntas da ficha foram divididas em três grandes categorias (recolha de informações, interpretação e readequação das atividades).

Essa divisão, proposta por categorias, permite perceber se o estudante foi capaz de identificar pontos importantes para seu processo de aprendizagem, tais como: qual o assunto que norteou a interação, as estruturas linguísticas desenvolvidas, assim como os pontos positivos da conversa e os que necessitam ser estudados novamente.

Para cada interação oral foi preenchida uma ficha de autoavaliação, num total de vinte e quatro fichas para a análise desse estudo. Os participantes serão identificados como E1, E2, E3, E4 e E5, sendo que E é a abreviatura de estudante.

Com o objetivo de exemplificar as análises realizadas a partir das respostas das questões da ficha de autoavaliação será trazido à baila excertos dessas respostas dos estudantes participantes do projeto.

Para finalizar essa seção é importante ressaltar que a versão da ficha para análise proposta aqui foi elaborada antes do início das interações dos estudantes, permitindo, dessa forma, trazer considerações preliminares sobre o uso da mesma. 


\section{SEMINÁRIO DE PESQUISA EM CIÊNCIAS HUMANAS - SEPECH \\ Humanidades, Estado e desafios didático-científicos \\ Londrina, 27 a 29 de julho de 2016}

\section{CONSIDERAÇÕES PRELIMINARES}

Embora parciais, os resultados obtidos até o momento já são significativos em relação à aprendizagem dos estudantes brasileiros.

Um primeiro apontamento nos permite verificar que a ficha de autoavaliação ajuda o estudante a recolher informações a partir das metas e objetivos propostos para cada prática de interação online (perguntas 1, 2 e 3), fomentando a interpretação dessas informações recolhidas durante as interações (perguntas 4, 5 e 6) e propondo readequações necessárias a sua aprendizagem (perguntas 7 e 8).

É possível verificar que a ficha de autoavaliação corrobora as fases do processo de regulação apresentadas por Pinto e Santos (2006) e visam permitir que o estudante reflita sobre seu processo de aprendizagem e proponha melhorias para a mesma, tornando-se um ator ativo desse processo, sendo, aqui, legitimada através das anotações realizadas pelos estudantes na ficha e trazidas através de excertos.

\section{Excerto 1:}

Questão 1 - Qual o assunto estudado na sessão?

E1: Falamos sobre gostos e preferências.

E2: Perguntas sobre rotina.

E3: A cultura brasileira.

\section{Excerto 2:}

Questão 4 - Marque com um X as alternativas que você considera ter aprendido na sessão de hoje.

E2: Gramática e Pronúncia.

E3: Pronúncia.

E4: Vocabulário e pronúncia.

4.1 - Exemplifique os itens marcados.

E2: Na gramática, consegui fazer perguntas sobre a rotina dele.

E3: Eu pronunciei melhor as palavras e entendi ele melhor também.

E4: Eu falei sobre a minha rotina e fiz perguntas com o DO. Ele me corrigiu em relação aos dias e meses do ano.

\section{Excerto 3:}

Questão 7 - O que você acha que precisa melhorar?

E2: Preciso me soltar mais. Me sinto muito insegura.

E4: Preciso me dedicar mais. Não estudei em casa e tive dificuldade de entender o que ele disse.

E5: A timidez é um problema, porque gaguejo ao falar. Preciso praticar mais em casa.

Foi possível perceber também um maior envolvimento dos estudantes com seu próprio processo de aprendizagem, além de uma atuação mais consciente nesse processo, prova disso é a motivação dos estudantes ao perceberem-se compreendidos pelos participantes estrangeiros que não sabiam nada ou quase nada da língua portuguesa, entende-se, pelas respostas, que o sentimento de empatia ao se colocar no lugar do outro e perceber que as dificuldades são fatores presentes dos dois lados 


\section{SEMINÁRIO DE PESQUISA EM CIÊNCIAS HUMANAS - SEPECH \\ Humanidades, Estado e desafios didático-científicos \\ Londrina, 27 a 29 de julho de 2016}

promove um sentimento de segurança e os motiva a investir nas interações e consequentemente no próprio processo de aprendizagem.

\section{Excerto 4}

Questão 3 - O que considera ter sido o momento de destaque de sua aprendizagem de hoje? Porquê?

E2: Gostei de perceber que o Ashan também teve medo de conversar em português. Isso me deixou mais segura.

E3: Quando falamos sobre nossas cidades, eu tirei muitas dúvidas com ele. Ele fez com que fosse confortável e que rendesse a conversa.

E4: Foi quando falamos sobre o que queremos ser no futuro. Porque saímos do roteiro e pudemos ter uma conversa na base do improviso.

Em relação ao professor responsável pelo projeto, é possível entender que seu papel é muito mais próximo e atuante junto ao estudante. Esse acompanhamento é mais trabalhoso e exige tempo para que as reflexões feitas a partir das fichas possam gerar atividades que atendam à necessidade de cada estudante, impactando também no currículo escolar.

Os resultados preliminares demonstram que a autoavaliação tem impacto positivo sobre a aprendizagem do estudante, entretanto a ficha, enquanto instrumento de análise, necessita de readequações para que ajudem o estudante a aprofundar e/ou direcionar as reflexões sobre seu processo de aprendizagem. Tais readequações já foram realizadas na ficha de autoavaliação e estão em fase de aplicação e serão apresentadas em outro estudo.

O estudo proposto aqui soma-se aos já realizados até o momento, citados na revisão de literatura, que apontam para novos caminhos a serem trilhados pelo professor de língua inglesa que tem como objetivo promover a aprendizagem para além da sala de aula. Tais caminhos nos remetem ao uso das TIC, ao contexto telecolaborativo, assim como novas formas de pensar a avaliação, tendo-a como uma aliada no desenvolvimento da autonomia e da corresponsabilidade pelo próprio aprender por parte do estudante, sendo assim reconhece-se a importância de voltar os olhos ao início de tudo, uma vez que, uma viagem de mil milhas começa com o primeiro passo ${ }^{5}$.

\section{REFERÊNCIAS}

BELZ, J.A. Social dimensions of telecollaborative foreign language study. Language Learning \& Technology. 2002. 6(1), 60-81. Disponível em: http://1lt.msu.edu/vol6num1/BELZ/default.html.

. From the special issue editor. Language Learning \& Technology, 2003a. 7(2):2-5. Disponível em: http://lit.msu.edu/vol7num2/speced.html.

${ }^{5}$ Lao-Tsé. Provérbio japonês. 


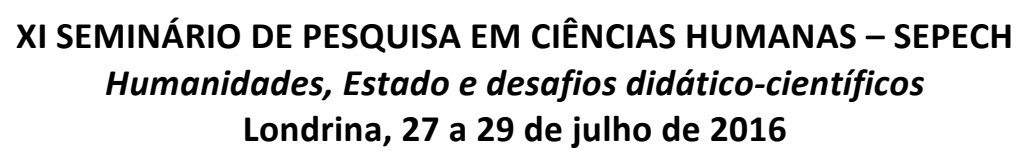

Linguistic perspectives on the development of intercultural competence in telecollaboration. Language, Learning \& Technology, 2003b. 7(2):68-117. Disponível em: http://1lt.msu.edu/vol7num1/belz/default.html.

BELLONI, M. L. Educação a distância 2.ed. São Paulo: Editora Autores Associados, 1999.

BRASIL, Secretaria de Educação Básica. Orientações Curriculares para o Ensino Médio. Linguagens, códigos e suas tecnologias. Brasília, 2006. Disponível em: http://portal.mec.gov.br/seb/arquivos/pdf/book_volume_01_internet.pdf

CAVALARI, S. M. S. A definição das metas e o processo de autoavaliação no contexto de teletandem. In: VIEIRA-ABRAHÃO M.H.; CONSOLO D. A.; BENEDETTI A. M. Pesquisas em Ensino e Aprendizagem no TELETANDEM BRASIL. Campinas, SP. Pontes Editores, 2010.

CLAVEL-ARROITIA, B.; PENNOCK-SPECK, B. Telecollaboration in a secondary school context: Negotiation of meaning in English as a lingua franca/Spanish tandem interactions.@tic. revista d'innovació educativa. 15. 2015: 74- 81. Disponível em: https://ojs.uv.es/index.php/attic/article/view/6411

COELHO, D.; GALANTE, A.; PIRES A. L. Online collaboration for English learners: Implementing an International Project with Edmodo. TESL-EJ, v.19, no 4, 2016. Disponível em: http://www.tesl-ej.org/wordpress/issues/volume19/ej76/ej76int/

COSTA, M. Autoavaliação: representações e práticas de professores de Língua Inglesa. In: $\mathrm{X}$ Congresso Internacional Galego-Português de Psicopedagogia. Braga: Universidade do Minho, 2009. Anais... Disponível em: http://www.publicacoesacademicas.uniceub.br/index.php/face/article/view/48/98.

Acesso em: 20 abril 2015.

FINO, C. N. Vygotsky e a zona de desenvolvimento próxima (ZDP): Três implicações pedagógicas. Revista Portuguesa de Educação. Vol. 14, no 2, p. 273-291. Disponível em: http://www3.uma.pt/carlosfino/publicacoes/11.pdf. Acesso em: 10 jan. 2015.

FURTOSO, V. A. B. Desempenho oral em Português para falantes de outras línguas: Da avaliação à aprendizagem de línguas estrangeiras em contexto online. Tese (Doutorado) - Instituto de Biociências, Letras e Ciências Exatas, Universidade Estadual Paulista, São José do Rio Preto, 2011.

GARCIA, D. N. M. O professor e a prática telecolaborativa no teletandem. The ESPecialist, vol 32, no 1 p. 81-108, 2011

HADJI, C. A avaliação, regras do jogo: das intenções aos instrumentos. Portugal: Porto Editora, 1994. 


\section{SEMINÁRIO DE PESQUISA EM CIÊNCIAS HUMANAS - SEPECH \\ Humanidades, Estado e desafios didático-científicos \\ Londrina, 27 a 29 de julho de 2016}

JUNCKES, R. S. A prática docente em sala de aula: Mediação Pedagógica. In: Simpósio sobre Formação de Professores: Educação Básica: Desafios frente às desigualdades Educacionais. 2013. Universidade do sul de Santa Catariana. Anais... Disponível em: http://linguagem.unisul.br/paginas/ensino/pos/linguagem/eventos/simfop/artigos_v\%20s fp/Rosani Junckes.pdf. Acesso em: 15 ago. 2015.

LANTOLF, J. P.; THORNE, S. L.; POEHNER, M. E. Sociocultural theory and second language development. In: B. VanPatten \& J. Williams (Eds.), Theories in second language acquisition: An introduction. New York, NY: Routledge. 2015. 2nd ed. pp. $207-226$.

LUCKESI, C. C. Avaliação da aprendizagem escola: estudos e proposições. 19 ed. São Paulo, Cortez, 2008.

MARCUSCHI, L. A. Gêneros textuais emergentes no contexto da tecnologia digital. In: MARCUSCHI, L. A.; XAVIER, A. C. (Orgs.) Hipertexto e gêneros digitais. Rio de Janeiro: Editora Lucerna, 2004.

NUNES, E. M. S.; RAMOS W. C. Aprendizagem de línguas in-tandem: um suporte inovador na aprendizagem de língua inglesa. Horizontes de Linguística Aplicada, Brasília, ano 10 v. 1, p.110-132, jan/jul. 2011.

OLIVEIRA. C. C. A auto regulação da aprendizagem. Publicações Acadêmicas v. 3, n. 22006 Centro Universitário de Brasília. Disponível em: $<$ http://www.publicacoesacademicas.uniceub.br/index.php/face/article/view/48>.

Acesso em: 30 mar. 2015.

PAIVA, V. L. M. O. A sala de aula tradicional X a sala de aula virtual. In: Congresso de Associação de Professores de Língua Inglesa do Estado de Minas Gerais, 3, 2001, Belo Horizonte, In: Anais... Belo Horizonte, 2001. p.129-145. Disponível em: $<$ http://www.veramenezes.com/virtual.htm>. Acesso em:17 set. 2015.

PINTO, J.; SANTOS, L. Modelos de avaliação das aprendizagens. Lisboa: Universidade Aberta. 2006

PRIMO, A. Interação mútua e reativa: uma proposta de estudo. Revista da Famecos, n. 12, p. 81-92, jun. 2000.

SANTAELLA, L. Comunicação ubíqua: Repercussões na cultura e na educação. São Paulo: Editora Paulus, 2013, p.294-307.

SCARAMUCCI, M.V.R. O professor avaliador: Sobre a importância da Avaliação na Formação do Professor de Língua Estrangeira. In: ROTTAWA L. \& SANTOS S.S. (Org.) Ensino e aprendizagem de línguas: línguas estrangeiras Ijuí, Unijuí, 2006. p.49-64. 


\section{SEMINÁRIO DE PESQUISA EM CIÊNCIAS HUMANAS - SEPECH \\ Humanidades, Estado e desafios didático-científicos \\ Londrina, 27 a 29 de julho de 2016}

TELLES, J. A. Teletandem Brasil - línguas estrangeiras para todos: ensinando e aprendendo línguas estrangeiras in-tandem via MSN Messenger. UNESP, 2006 In: http://www.teletandembrasil.org/site/docs/TELETANDEM_BRASIL_completo.pdf

TELlES, J. A.; VASSALlO M. L. Teletandem: Uma proposta alternative no ensino/aprendizagem assistidos por computadores. In: TELLES, J. A.(Org) Teletandem: Um contexto virtual, autônomo e colaborativo para aprendizagem de línguas estrangeiras no século XXI. Campinas, SP: Pontes Editores, 2009.

VIEIRA I. M. A. A autoavaliação como instrumento da aprendizagem. Dissertação (Mestrado) Departamento de Educação e Ensino a Distância. Universidade Aberta. Lisboa, 2013. 